\title{
Preparation and Characterization of ZnSe Film Synthesized by Chemical Co-reduction
}

\author{
Kegao LIU ${ }^{1, a^{*}}$, Nianjing $\mathrm{JI}^{2, \mathrm{~b}}$, Yong $X \mathrm{U}^{1, \mathrm{c}}$, Guangcai $\mathrm{SHI} \mathrm{I}^{3, \mathrm{~d}}$ \\ ${ }^{1}$ School of Materials Science and Engineering, Shandong Jianzhu University, Fengming Road, Jinan \\ 250101, China \\ ${ }^{2}$ State Key Laboratory of Crystal Materials, Shandong University, 27 Shandanan Road, Jinan \\ 250100, China \\ ${ }^{3}$ Shandong Bureau of China Metallurgical Geology Bureau, Jinan 250101, China \\ aliukg163@163.com, bjnj33jn@126.com, 'xuyong2612@gmail.com, ${ }^{\text {d}}$ Shi-gc9506@126.com \\ ${ }^{*}$ Corresponding author: Kegao Liu
}

Keywords: Zinc Selenide, phase, morphology, chemical co-reduction.

\begin{abstract}
Binary ZnSe thin films were prepared by spin-coating and chemical co-reduction, the effects of reaction conditions on thin films were investigated. The phases of obtained samples were characterized by X-ray diffraction (XRD). The size and morphology of the products were observed by scanning electron microscope (SEM). Experimental results show that, the product sample with high XRD peaks obtained at $200{ }^{\circ} \mathrm{C}$ has better crystallinity than those obtained at lower temperatures, which indicates that high temperature was in favor of crystallization; Longer reaction time and low speed spin-coating are also beneficial to crystallization of ZnSe films. Single phase ZnSe thin film with special morphology was prepared by low speed spin coating and reacting for $60 \mathrm{~h}$ with ethylene glycol as the solvent on the glass substrate.
\end{abstract}

\section{Introduction}

Zinc Selenide (ZnSe) with about $2.7 \mathrm{eV}$ band gap can be used for optical windows, lenses, mirrors, prisms and optical blanks, slabs particularly for infrared applications due to its extremely low bulk losses, high resistance to thermal shock and stability [1-3]. The efficiency of the solar cell with $\mathrm{Cu}(\mathrm{In}, \mathrm{Ga})(\mathrm{Se}, \mathrm{S})_{2}$ buffer layer prepared by chemical vapor deposition has reached 9.6\% in 2000 [4]. The CIGSS/Zn(Se,OH $)_{x}$ heterojunction with conversion efficiency $13.6 \%$ was reported by A.Ennaoui et al in the same year [5]. Indian Kale prepared yellow ZnSe thin film by chemical bath deposition with $\mathrm{Zn}\left(\mathrm{CH}_{3} \mathrm{COO}\right)_{2}$ and $\mathrm{Na}_{2} \mathrm{SeSO}_{3}$ as raw materials, which has about $2.85 \mathrm{eV}$ bandwidth and good combination with glass substrate [6]. ZnSe film with (111) preferential growth was successfully prepared by thermal evaporation technique at room temperature on the glass substrate [7]. In this work, the yellow ZnSe thin films with single phase were synthesized by spin coating and co-reduction. The effects of reaction temperature, time and the frequency of spin coating on $\mathrm{ZnSe}$ film and the film morphology were investigated.

\section{Experimental}

The substrates (glass or silicon) were cleaned in sulfuric acid for $30 \mathrm{~min}$, and then cleaned by ultrasonic in acetone and ethanol respectively for $20 \mathrm{~min}$. They were kept in ethanol and be dried before using. The precursor solution consists of $\mathrm{ZnCl}_{2}$ and $\mathrm{SeO}_{2}$ as raw materials with molar ratio of 1:1 in deionized water, ethanol or ethylene glycol. The precursor film with a certain thickness were prepared by repeated spin coating under conditions of low speed $400 \mathrm{r} / \mathrm{min}$, high-speed $3000 \mathrm{r} / \mathrm{min}$ and rotation time $5 \sim 20 \mathrm{~s}$ for the spin coating machine. The precursor film on the substrate was placed in the reaction vessel with $1 \mathrm{~mL}$ hydrazine hydrate as reducing agent and reacted at $160 \sim 200{ }^{\circ} \mathrm{C}$ for $10 \sim 60 \mathrm{~h}$. And then it was taken out for drying, the yellow ZnSe film can be obtained. The phases of obtained samples were characterized by X-ray diffraction (XRD) on a model of Bruker 
D8 Advance XRD system with Nifiltered Cu-Ka $(\lambda=1.5059 \AA)$. The size and morphology of the products were observed by JSM6380LA electron microscope (SEM).

\section{Results and discussion}

\section{The effect of reaction temperatures on $\mathrm{ZnSe}$ phase formation}

Fig. 1 shows the XRD patterns of ZnSe thin film samples obtained with deionized water as solvent at different temperatures on the glass substrate, which reacting conditions are reacting time $20 \mathrm{~h}$ and at $180{ }^{\circ} \mathrm{C}$ for a) and $200{ }^{\circ} \mathrm{C}$ for b) respectively, Fig.1c is the pattern for the sample b that the peak of $\mathrm{NaCl}$ was removed. According to the standard PDF card (No.70-0777) of ZnSe, it can be known that the XRD peaks at $2 \theta$ angles of $27.4^{\circ}, 45.5^{\circ}$ and $53.9^{\circ}$ are corresponding to (111), (220) and (311) crystal planes respectively. These three XRD peaks are similar to the results of ZnSe thin films prepared by Jeewan Sharma using inert gas condensation method, and the ZnSe films they obtained have preferential growth along (111) crystal plane [8]. From Fig.1 it can be seen that the XRD intensity of product ZnSe film with $\mathrm{NaCl}$ impurity is not high. Compared Fig.1a with Fig.1c, the crystallinity of the product film sample obtained at $200{ }^{\circ} \mathrm{C}$ is better than that obtained at lower temperatures, which indicates that high temperature is in favor of ZnSe crystallization.
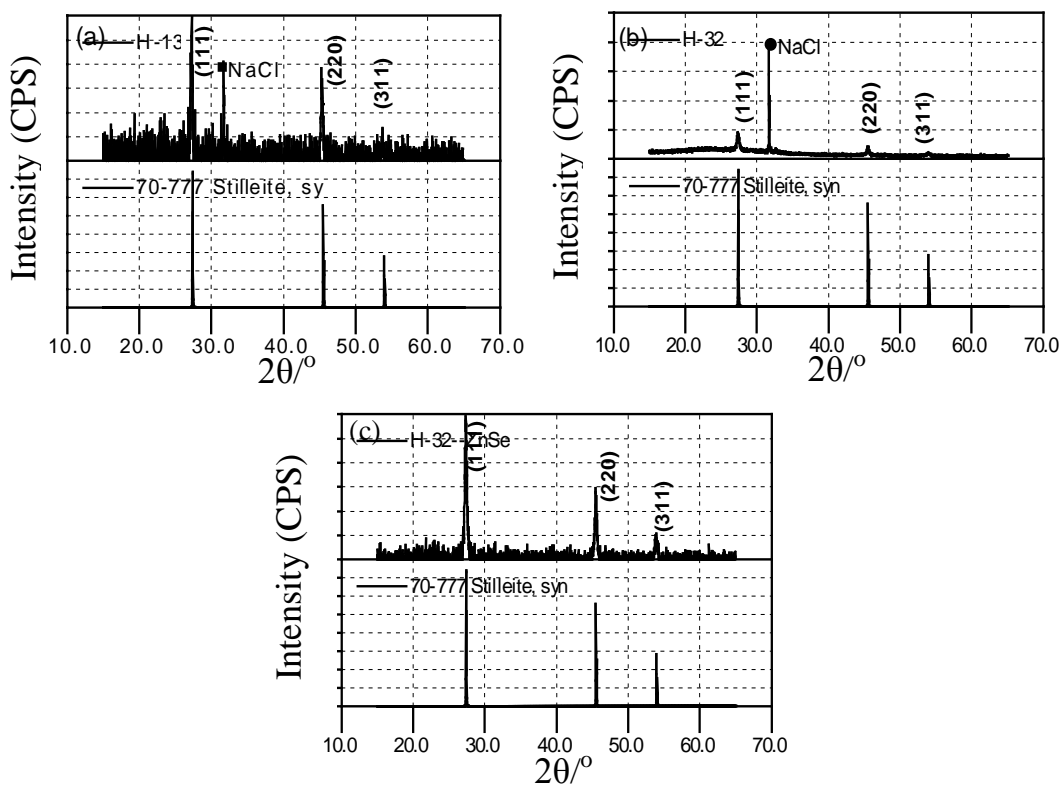

Fig.1 XRD patterns of ZnSe thin film samples obtained at different temperatures

\section{The effect of reaction time on ZnSe phase formation}

Fig. 2 shows the XRD diffraction patterns of ZnSe thin films obtained under conditions of ethanol as solvent, silicon substrates, $200{ }^{\circ} \mathrm{C}$ for $10 \mathrm{~h}$ and $20 \mathrm{~h}$ respectively. The strong XRD peak at $2 \theta 32.9^{\circ}$ belongs to $\mathrm{NH}_{4} \mathrm{Cl}$ impurity phase along crystal plane (110) according to the PDF Card (No.1-1044). Compared Fig.2a with Fig.2b, it is clearly seen that the crystallinity of the product film reacted at $200{ }^{\circ} \mathrm{C}$ for $20 \mathrm{~h}$ was better than that reacted at $200{ }^{\circ} \mathrm{C}$ for $10 \mathrm{~h}$, which demonstrates that longer reaction time is conducive to crystallization.

\section{The effect of spin coating speed on product films}

Fig. 3 shows XRD patterns of ZnSe thin film samples prepared with different spin-coating speeds, 400r/min for Fig.3a with 30s, 3000r/min for Fig.3b with 30s. Other experimental conditions were $200{ }^{\circ} \mathrm{C}$ for $20 \mathrm{~h}$, ethylene glycol as solvent, silicon substrates and spin coating eight times. Compared Fig.3a with Fig.3b, The product sample obtained with low spin coating speed has better crystallinity than that obtained with high speed.

\section{Preparation of ZnSe thin film with single phase}

By adjusting reaction temperature and prolonging reaction time, the product film with single phase $\mathrm{ZnSe}$ was obtained. Fig. 4 shows the XRD pattern of the product film sample obtained at $180^{\circ} \mathrm{C}$ for 60 
$\mathrm{h}$ with ethylene glycol as solvent, it indicates that ZnSe thin film with single phase can be obtained with low spin coating speed on the glass substrate. The XRD peaks at $2 \theta$ angles of $27.4^{\circ}, 45.5^{\circ}$ and $53.9^{\circ}$ are also corresponding to (111), (220) and (311) crystal planes respectively.
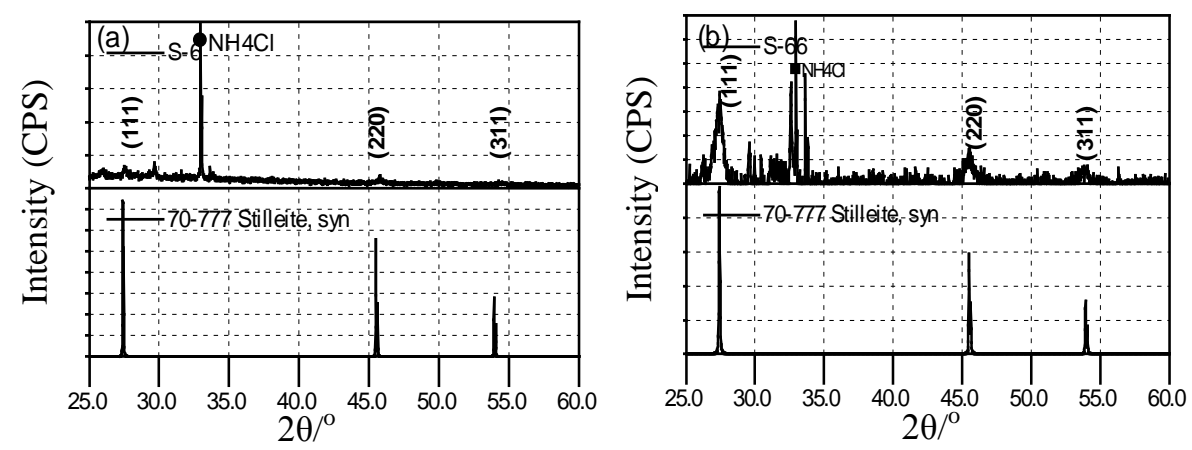

Fig.2 The XRD pattern of the ZnSe thin film sample obtained with different reaction time $\begin{array}{ll}\text { a) } 200{ }^{\circ} \mathrm{C} \text { for } 10 \mathrm{~h} & \text { b) } 200{ }^{\circ} \mathrm{C} \text { for } 20 \mathrm{~h}\end{array}$
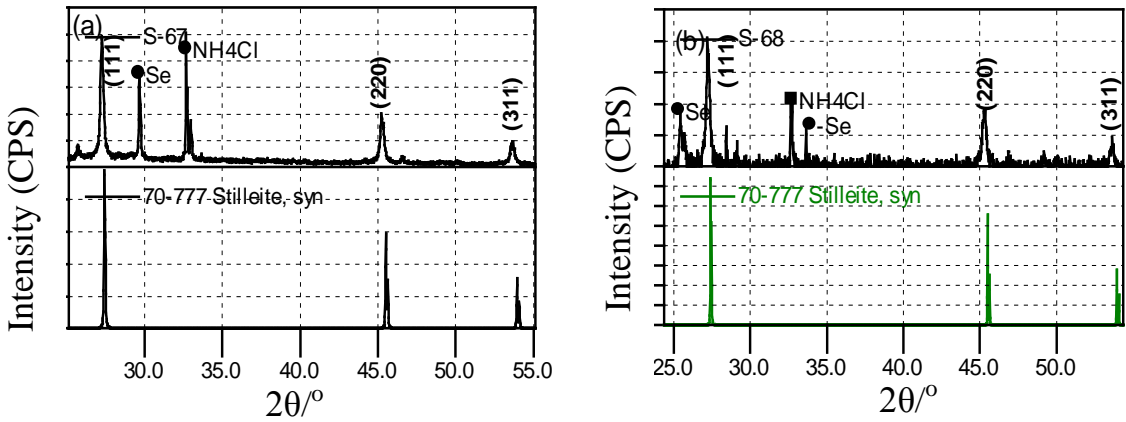

Fig.3 XRD patterns of ZnSe thin film samples prepared with different spin-coating speeds a) $400 \mathrm{r} / \mathrm{min}$ for $30 \mathrm{~s}$, b) $3000 \mathrm{r} / \mathrm{min}$ for $30 \mathrm{~s}$

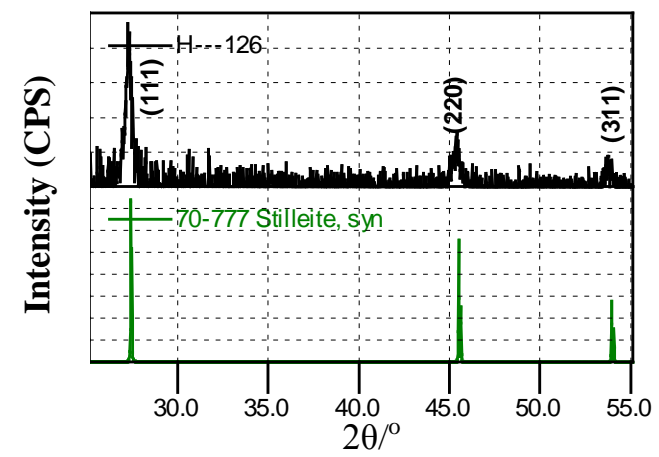

Fig.4 The XRD pattern of the ZnSe thin film sample obtained at $180{ }^{\circ} \mathrm{C}$ for $60 \mathrm{~h}$

Fig. 5 shows the SEM images of the product sample with single phase ZnSe obtained at $180{ }^{\circ} \mathrm{C}$ for $60 \mathrm{~h}$. It can be seen that the film with special morphology is uncontinuous. There are many rings distributing on uniform circular particles. Among which a few of ring is not completely closed with radius of $0.1 \sim 1.5 \mu \mathrm{m}$ and wall thickness about $0.2 \sim 0.4 \mu \mathrm{m}$.

\section{Analysis of ZnSe thin film synthesizing mechanism}

The reaction mechanism of this process, is that the precursor film sample was placed in a reaction vessel and heated, $\mathrm{Zn}$ and Se atoms were easily reduced by $\mathrm{NH}_{2}-\mathrm{NH}_{2}$, which were very active and easy to combine to form $\mathrm{ZnSe}$ compound. The main reactions are as follows.

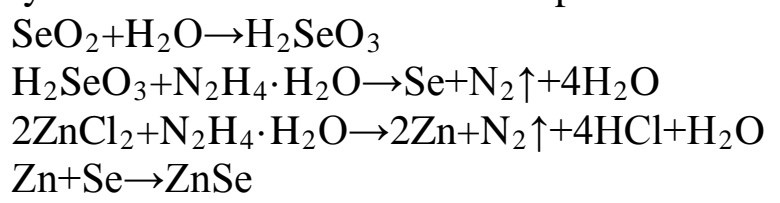




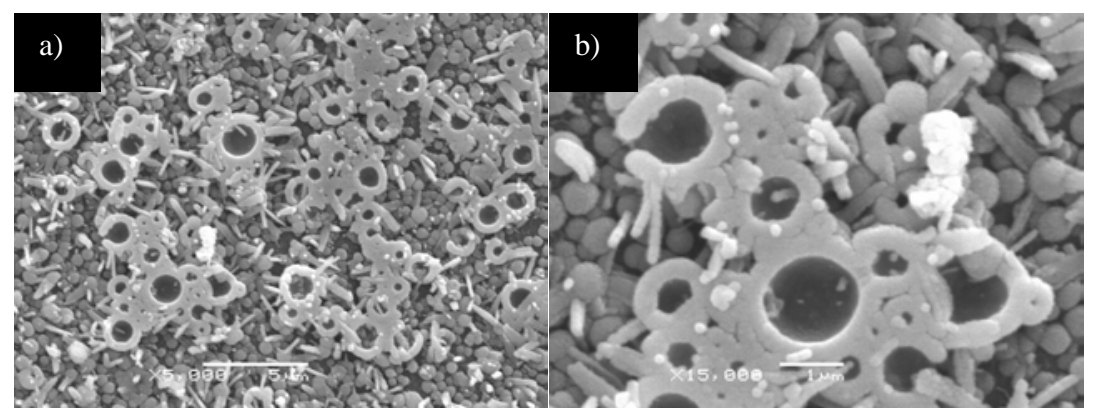

Fig.5 SEM images of the ZnSe thin film sample obtained at $180{ }^{\circ} \mathrm{C}$ for $60 \mathrm{~h}$

\section{Conclusions}

Binary ZnSe thin films were prepared by spin-coating and chemical co-reduction, the effects of reaction conditions on thin films were investigated. The product sample with high XRD peaks obtained at $200{ }^{\circ} \mathrm{C}$ has better crystallinity than those obtained at lower temperatures which indicates that high temperature was in favor of crystallization; The crystallinity of ZnSe film sample obtained by reacting $20 \mathrm{~h}$ was better than those obtained by reacting $10 \mathrm{~h}$ which indicates that longer reaction time was also beneficial to crystallization of ZnSe films; The crystallization of ZnSe thin film obtained by low speed spin-coating is better than others. Single phase ZnSe thin film with special morphology was prepared by low speed spin coating and reaction $60 \mathrm{~h}$ with ethylene glycol as the solvent on the glass substrate.

\section{Acknowledgment}

This work was financially supported by the National Natural Science Foundation of China (No.51272140).

\section{References}

[1] W.P. Rao, Y. Wang, Y.G.Zhang, X.Liu, Influences of deposition temperature and rate on mechanical stress of electron beam deposited ZnSe thin films, Journal of Zhejiang University (Engineering Science), 43 (2009)2059-2061.

[2] Information on http://wenku.baidu.com/.

[3] Information on http://www.edmundoptics.com/.

[4] A. Rumberg, Ch. Sommerhalter, M. Toplak, ZnSe thin films grown by chemical vapour deposition for application as buffer layer in CIGSS solar cells, Thin Solid Films, 361-362 (2000) 172-176.

[5] A. Ennaoui, M. Weber, M. Saadb, Chemical bath deposited $\mathrm{Zn}(\mathrm{Se}, \mathrm{OH})_{\mathrm{x}}$ on $\mathrm{Cu}(\mathrm{In}, \mathrm{Ga})(\mathrm{S}, \mathrm{Se})_{2}$ for high effciency thin film solar cells: growth kinetics, electronic properties, device performance and loss analysis, Thin Solid Films, 361-362 (2000) 450-453.

[6] R.B. Kale, C.D. Lokhande, R.S. Mane, Sung-Hwan Han. Use of modified chemical route for ZnSe nanocrystalline thin films growth: Study on surface morphology and physical properties. Applied Surface Science, 252 (2006) 5768-5775.

[7] Taj Muhammad Khan, Muhammad Farhan Mehmood, Synthesis of thermally evaporated ZnSe thin film at room temperature. Thin Solid Films, 519 (2011) 5971-5977.

[8] Jeewan Sharma, S. K. Tripathi, Effect of deposition pressure on structural, optical and electrical properties of zinc selenide thin films. Physica B, 406 (2011) 1757-1762. 